Interviewer: Okay. This is *** on Friday, April 18th. I'm here with $* * *$

Interviewee: $* * *$.

Interviewer: $* * *$. It is the winter semester. $\mathrm{xx}$, my first question today is how would you describe yourself as a writer?

Interviewee: Hmm, so I guess basically I've always really liked writing and I think, originally, I liked writing because people said I was good at it. I don't know. I've definitely changed as a writer. I think where I started was just fulfilling assignments and doing a good job with that. Now, I really push myself to, I think, be more creative with my writing. I never saw myself as a creative writer but I've actually really started to enjoy that aspect of it.

Interviewer: What catalyzed that change?

Interviewee: It was actually the Gateway course for the minor in writing.

Interviewer: Okay.

Interviewee: We had to do a lot of free writing, which I hated, but then as I started doing it I started to enjoy it more as I got more comfortable with it.

Interviewer: Okay. Great. Anything else? How would you describe yourself when you first came here versus now? Are there any other ways that you have grown or changed as a writer? You've tended to be more creative. Are there any other aspects of your writing that have changed?

Interviewee: I think this kind of is along those lines but I'm just less [pause]-I don't know how to say this. I guess less focused on-I used to be really grammar and that kind of oriented and now as a-stylistically I like to just do whatever I want [laughter].

Interviewer: Interesting. Because of the free writing or what do you think led to that?

Interviewee: I don't know. I kind of like how it sounds better; more like stream of consciousness-like writing.

Interviewer: Cool. Were there any other events or experiences that you had that informed the way that you were writing here?

Interviewee: Not really [laughter].

Interviewer: Okay. As you graduate what are your goals for yourself as a writer? 
Interviewee: I don't really know that-I don't know. It's weird because I'm applying to med school so aside from writing a personal statement and explaining myself in the application I don't really see myself doing much writing from here on out.

Interviewer: I see. Are there any goals - sort of abstractly ways that you wish your writing would improve even if you don't see yourself necessarily doing a lot of writing?

Interviewee: No. I think the most important thing that writing has helped me improve is communication skills and that's something that, obviously, I'm gonna need for the rest of my life.

Interviewer: $\mathrm{Mm}-\mathrm{hmm}$.

Interviewee: Just kind of being able to organize your thoughts and put together some kind of argument, I guess, is an important skill.

Interviewer: Cool. Yeah. How well do you feel like you do that at this point?

Interviewee: I think I can do that pretty successfully now. You know you can always be better at it, I guess.

Interviewer: Mm-hmm, mm-hmm. Any other ways that you would hope to change as a writer?

Interviewee: Not that I can really think of [laughter].

Interviewer: Yeah. It's pretty abstract. Thinking across your writing experiences at U.M [University of Michigan]. what do you think it means to write well? What does good writing mean? What are the qualities?

Interviewee: I think, coming back to the idea of communication, if you can get an idea across such that people understand it as you intended then you've done your job.

Interviewer: Got it. Clarity.

Interviewee: Yeah.

Interviewer: Anything else?

Interviewee: I guess all of the things that go into that; just like the organization of how you put something together. You have to get the information across in a way 
that's suited for your audience, obviously. Everything that goes with that; presenting an idea.

If you can present an idea-like I don't think it necessarily comes down to having perfect grammar or perfect spelling. Really, just if people understand what you're trying to say.

Interviewer: I see. It's interesting because you were talking about getting so involved in creative writing and I wonder to what extent does creative writing does or does not encourage a clarity or an organization-focused approach? How do you feel like those two things relate to each other?

Interviewee: I don't know.

Interviewer: If at all.

Interviewee: I guess when you say, “Creative writing” I'm-I don't know if creative-like I don't do fiction. It's not fiction; I don't write fiction but I guess it was more writing more personally-

Interviewer: I see.

Interviewee: - as opposed to creatively.

Interviewer: I see.

Interviewee: More personal and kind of just more spontaneous, I guess. Because I had to do in-class writing it was like, "Okay, write for ten minutes," and so you just have to go, you know, without planning?

Interviewer: Right.

Interviewee: Which is hard. Then I don't know [laughter].

Interviewer: Mm-hmm, yeah. Were there any other specific assignments in that class or in other classes that fed into your writing process or your writing values?

Interviewee: [Pause] I took [an English course] that was about hip hop and arguments within hip hop. That was actually really interesting and one of the papers that I had to write I really struggled with and I met with my professor a lot. She pushed me to organize my paper in a completely different way than I currently had it because how I had it just wasn't really working.

That was kind of like a cool experience in doing something completely different and in a way that I hadn't ever thought of before. I had to write an essay about a song and then incorporate scholarly articles from hip hop scholars and stuff like 
that and it did incorporate a lot of sources and usually I feel like you go into it and you're like, "Okay, I'll organize it by topic and then put all the sources wherever they fit."

She encouraged me to organize it by source, actually, and lead it through that way which is something I never would've thought of. I don't even know if I would do that again on my own but it was just really cool to try doing that.

Interviewer: How did that influence your argument or your paper by reorganizing it like that?

Interviewee: I think I actually really, really know what I was trying to say-

Interviewer: Hmm, interesting.

Interviewee: - yeah "cuz I had to make sure the "I" 00:07:58 was totally solid on the argument before I-it was almost like I couldn't fall back on dropping a source here or there. I had to know exactly what I was saying and then be able to incorporate everything together.

Interviewer: Awesome. That's a good transition into this next question, which is what upper-level writing courses have you taken? Talk a little bit about your experiences in those courses.

Interviewee: The upper-level writing class that I took for the minor was [Writing course] to be a Sweetland Peer tutor.

Interviewer: $\mathrm{Mm}-\mathrm{hmm}$.

Interviewee: That class was really cool. We obviously spent a lot of time talking about tutoring philosophy and stuff but it was really cool to see-I think that was maybe not the first time but probably the most influential class and just seeing writing as a whole process as opposed to just working toward the end goal.

Because we talked so much about helping people at different stages of writing and ways that you can do that.

That class was really cool. I also took a writing and biology class that's through the bio [biology] department. That class was more just understanding the world of scientific research and the different ways that you have to communicate, depending on what it is that you're trying to tell people or show people. That was really interesting, too.

Interviewer: Going back to your first course, the peer tutoring course-

Interviewee: $\mathrm{Mm}-\mathrm{hmm}$ ? 
Interviewer: - you talked about having to figure out the different stages of the writing process-

Interviewee: Yeah.

Interviewer: - as you led people through the writing process. Can you talk about what you see as the stages of the writing process?

Interviewee: I think it really depends on what you're doing but for a standard essay you're writing for class, I guess, you have to try to plan it out first and figure out what you want to write about, then what you have that you can say about it. Then, from there you have to just organize into-I don't know-a lot of people do outlines.

I guess I kind of do outlines when I do that kind of stuff. Then just write, I guess, and revise a bunch of times. I haven't really written an academic — what I would consider an academic essay_ _ in a long time.

Interviewer: Huh. We need to have bookmarked that. [Laughter]

Interviewee: [Laughter]

Interviewer: You talked about just writing and then revising. Could you break that down? When you're writing what are some things? How do you go through and just draft it all? Like some process for that?

Interviewee: I mean I just write. I just start writing, usually following some kind of outline, depending on what I'm doing. The stuff I've been writing lately I just sit down and write it. I don't know. I think I just maybe have a knack for organizing things in my head or things just kind of fit together logically.

Obviously, I go back and do some rearranging and stuff but for the most part I've always been like-I spend a lot of time putting out a good first draft as opposed to just writing a bunch of stuff and then scrapping it.

Interviewer: How does your revision process work?

Interviewee: Usually reread stuff. Usually get feedback from either professors or some of my friends. Then, usually I need to expand on things more; that's pretty common, I think. Usually it's seeing and finding places that I can expand on or add more detail. Then I just go through and add in different places or rearrange things.

Interviewer: Did you learn anything else from looking at peer writing? 
Interviewee: [Pause 00:12:28-00:12:41] I don't know [laughter].

Interviewer: [Laughter]

Interviewee: It's a hard question. Not really, I guess. Yeah, it was mostly just seeing it as a whole process and everything involved with that.

Interviewer: How about in bio [biology] class? What were some of the essays you had to do and what did you learn along the way?

Interviewee: I had to write a profile of someone in the research community and so that was actually really cool because a lot of our assignments were really justhad a bunch of questions on them. The assignment sheets had a bunch of questions that you had to answer and you probably could've gotten the points for just following the same structure on the assignment sheet and answering the questions but I felt that was kind of boring.

I wrote mine more kind of like a feature that you would see and I don't - maybe like a newspaper or something. It was definitely more creative than just answering the questions. That was actually really fun because I realize that I did still want to do that kind of writing even in a class that didn't really ask for it.

Interviewer: Huh.

Interviewee: Then other stuff that we had to do definitely had to be more structured. One of them we had to review grants and so we had to - that had to be very specific and plan out specific parts of the 20-page grant proposals and talk through that and analyze that and then present it to the class. Another thing we had to do was analyze a pseudo-scientific ad and talk about what they-

Interviewer: [Laughter]

Interviewee: - use to appeal to the public and whether they try to scare you using scientific-sounding stuff even if it's not really scientific. That was cool.

Interviewer: What did you take away from that class in terms of learning writing or how did your writing change?

Interviewee: I don't really think that class affected my writing.

Interviewer: Okay.

Interviewee: It more just showed me how the research - the world of researchworks but in terms of the actual writing they were pretty straightforward assignments - I don't really think it took me that much. 
Interviewer: Okay. That makes sense. Let see. When was the last time that you wrote an academic research paper? I'm curious.

Interviewee: I think it was last year. I guess it was last year, yeah. I took evolution and so I had to write a research paper as my final paper. That was definitely research oriented; I had to read a bunch of studies and so I did kind of outline that. Yeah.

I mean I guess I've written some this semester for-I'm in medical anthropology so I've had to write two papers for that. Those I procrastinated and so I wrote those in a few hours and then turned them in so [laughter] I wouldn't really count that.

Interviewer: Got it. Were there any other-thinking about those two courses, the peer-tutoring course and the bio course, were there any other affects that those courses had on you as a writer?

Interviewee: Not really.

Interviewer: You said a lot already.

Interviewee: Yeah. I think some of the assignments for the [Writing course] I thought were kind of annoying [laughter].

Interviewer: Okay. How so?

Interviewee: It showed me the kind of writing that I don't want to have to do. I know we had to do this [...] essay that I also had to do again in the minor in writing so I had to do it twice, kind of. we were supposed to focus on-it's supposed to be kind of - not like a memoir but focus on a specific point in time that writing changed our - it just seemed like it was too - there was supposed to be this epiphany at some point in your life where writing changed you. I was like, 'That's not really true,' but I felt like I had to make something up to-

Interviewer: I see.

Interviewee: -fulfill the assignment. I don't like having to do that [laughter].

Interviewer: Got it. Do you still make use of what you learned in those courses in your writing now?

Interviewee: Not really. Those classes were so specific to certain things that I don't really feel like I took that much out of them in general. I don't know. It's not to say that they were a waste but when I try to think about what I got out of them I couldn't tell you. 
Interviewer: Sure, sure. What other writing courses have you taken? You did mention [English course].

Interviewee: $\mathrm{Mm}-\mathrm{hmm}$.

Interviewer: Can you talk about that in greater depth and any other writing courses throughout your time here? How have those courses affected your writing?

Interviewee: I took [English course] as a freshman and that - we just read four novels and then wrote a literary analysis of each one. We had to do a close reading and then that was the class; was four essays, four books. I really liked that class because the books were awesome and I did well so I really liked it.

It's funny because for the capstone course I just took for the minor we had to do this developmental essay and look back on our old writing and I hate all the stuff I wrote freshman year because it just sounds so stupid.

Interviewer: Why?

Interviewee: I just feel like I'm twisting everything to make some kind of argument that might not exist, which I feel like is what close reading is sometimes. Because I was like, "Oh, the author said this and it meant this," but it's like how does anyone even know that? I don't know. It just seemed like it was really forced.

That's what I talked about in my developmental essay; how a lot of what I wrote just feels very forced into some kind of argument, which I don't know if that's what the author thought or why they put that word there. You know? I guess it was good for forcing yourself to think more critically about things and to think about potential intentions but then there's not really a right or wrong answer, I guess.

Interviewer: If you were to write those essays over what would you do differently?

Interviewee: Oh, man [laughter]. I'd probably fall back into the same thing because that's what [laughter] I was used to. I don't know. It's hard because you want to be assertive about what you're saying and you don't want to keep saying, "The author could have meant this," you know?

Interviewer: Mm-hmm.

Interviewee: It's this weird thing and I feel like that just how literary analysis works is that you just make these bold claims and then back them up. I don't 
know if I would change anything. I think I just would rather not write one [laughter].

Interviewer: Okay. That's fair. Did you learn anything else from that class in terms of maybe overall writing skills? Not necessarily that particular genre of writing but how to write in that same, general...?

Interviewee: I don't know. That class was pretty specific to just how to do close reading. A lot of the time in that class was spent just discussing the books. I feel like we didn't actually talk about writing itself that much. I think I came in as a pretty strong writer just from the classes that I took in high school but I don't really think I improved as a writer throughout that class. I don't feel like we actually learned that much about writing. I don't know.

Interviewer: I see. The act of writing those four essays - maybe the focus was more on thinking about the reading?

Interviewee: I think it was more about the thinking than the actual writing, which, obviously, they go together [laughter]

Interviewer: Mm-hmm, yeah. Interesting. Any other writing courses at [University of Michigan] that you've taken?

Interviewee: Okay. That was freshman year and then I took [English course]. Oh, that was my junior year. What did I take- - Oh, sophomore year I took Writing 300. Now I've taken the gateway course for the minor and then a capstone and that's pretty much it.

Interviewer: Great. Well, we will talk about the capstone course in just a second but let's go back to the [English course] and the gateway. For [English course] did you talk more - anything that you haven't yet mentioned about what you took away from that aside from that one essay where your professor suggested you reorganize?

Interviewee: Yeah. That class was also kind of like very thinking heavy, I guess. I only wrote two papers in that class and then we wrote weekly blog posts. We wrote one blog post; we had to respond to everyone else's every week but I don't know. It's really hard to think of what [pause]-I think that my professor did a really good job pushing me because our first assignment was limited to three pages.

I had to be very concise [laughter] and I had to get an argument across in three pages. I know it was a close reading of song lyrics and - yeah, 'cuz originally I wanted to write out the whole song and then she was like, "You should just focus on one verse." It was kind of like the close reading stuff from freshman year; I was trying to say, "Oh, this meant this," or-you know? 
Interviewer: $\mathrm{Mm}-\mathrm{hmm}$.

Interviewee: I don't know if it did or not but I think I had to do more stuff that I hadn't done before. Like with the organizing sources and just really limiting myself to a really small number of pages; that was hard.

Interviewer: What effect did the blog post practice have on your writing?

Interviewee: Well, blog posts are always - I think they're a funny thing because there's the added element of peer pressure. Everyone else is reading it. I think I was more-I don't know that it really changed my writing that much but I just really enjoyed seeing the different ways that other people thought about stuff in ways that I didn't think about them. It was cool to just get exposure to so many different ideas. In terms of the actual writing of the blog post it was a couple hundred words; quick. Just like, "Do it."

Interviewer: I see.

Interviewee: Yeah.

Interviewer: Okay. How about the minor gateway? What were some of the things that you experienced in that course?

Interviewee: We had to do a lot of free writing, which I always hated. That was when I started to adopt a more stream-of-consciousness kind of style. Adding in extra little details, making it stylistic. I don't know. I liked the stuff we did in that class. We did a lot of little exercises that I thought were really cool to just-we had to do something called, "Why I Don't Write," before we wrote our "Why I Write."

That was the first piece that I think I was really proud of; that I really liked how it turned out. I wrote it just in one sitting. I edited it later and stuff but I put that in my capstone portfolio 'cuz I really like it. I don't know that the class, necessarily, taught me a lot because it was kind of do the projects and peer review other people's stuff. It wasn't really like, "This is how you write."

It was more an outlet for writing how you wanted, which I think was good for me. Also being pushed into doing more free writing stuff-I think that affected how I started writing 'cuz I was like, "Okay, I need to just write and keep my pencil moving." Once I got into that mindset it became a lot easier.

Interviewer: Mm-hmm, cool. Any other ways that that class impacted your writing or any exercises that you found enhanced your understanding of writing? 
Interviewee: I think incorporating more details into stuff. I'm trying to think if there were any specific - ? I know there was one in-class assignment that she asked us to describe our hometowns. I don't remember exactly what it was but each line - it was kind of like a poem type thing — and each line had to function in a certain way.

It was like, "Describe the sites; describe the sounds." Like that kind of thing. That was cool because it forced me to really focus on the details and I really liked providing really detailed stuff now. Not all the time but in certain places where I think it's appropriate.

Interviewer: Great. Any last remarks on any writing courses that you've taken? Upper level or lower level and that they've done?

Interviewee: Not really [laughter].

Interviewer: Okay. What is your concentration?

Interviewee: Biology.

Interviewer: Okay. Let's see. You talked about [Biology course]. Have you taken any other writing courses in your concentration?

Interviewee: No. Just that writing in bio [biology] class.

Interviewer: Got it. Now that you're about to graduate how confident do you feel about writing in your concentration?

Interviewee: [Pause] I feel pretty confident. I think that science writing is pretty formulaic in a lot of ways so if you had an example of something to look at you could probably mimic it. If you're writing a research paper you could pick up any other research paper from the same journal and follow the structure. Yeah, I could probably do it.

Interviewer: Have you learned anything else from even non-bio courses- just the regular English courses and the writing courses - that you were able to apply it to writing in your own concentration? To what extent has there been transfer between the writing courses in your concentration?

Interviewee: I mean just the standard being able to communicate an idea. You have to organize your stuff in a way that people can understand it. Other than that I-scientific writing is pretty different, I think, because they don't want the details. It's very straightforward. It's not really super exciting if you can use dashes and semicolons and vary sentence structure. It's pretty straightforward stuff- 
Interviewer: [Laughter]

Interviewee: - and the simpler the better, I think. That's where it's kind of limiting; I'm not really that interested in science writing probably for that reason.

Interviewer: Yeah, I see. Even though it's out of your concentration how often have you used skills or strategies from your writing classes in other courses here?

Interviewee: Any time I write something. I have standard things in mind that would just - what makes good writing, I guess. It's kind of like [laughter] standard stuff.

Interviewer: [Pause] To what extent do you feel like your definition of what makes good writing changes depending on what you're working on?

Interviewee: Yeah. I think it does depend what or who you're writing for, you know?

Interviewer: $\mathrm{Mm}-\mathrm{hmm}$.

Interviewee: Because I guess if you're writing a really professional piece it's really important for it to be perfectly polished. Then if you're writing maybe a more creative or personal piece maybe it's not as important that everything is perfect but it's more important that it has different elements, you know? I guess that matters.

Interviewer: $\mathrm{Mm}-\mathrm{hmm}$. Makes sense. Moving on to the capstone what impact has the [Writing course] had on your writing?

Interviewee: I don't really know that it's had that much of an impact [laughter].

Interviewer: Why's that?

Interviewee: I look back and think about what we did in this class and I don't really know. We wrote the developmental essay. It was cool to go back and look at my old writing but in terms of did it change me? No. The project was cool because I wrote two very personal stories that I haven't done personal writing before, really. That was cool. Again, it was cool but I don't know that it really changed me. It was kind of cool experiences but in terms of what I got out of it I don't really know.

Interviewer: What was the project about?

Interviewee: My project?

Interviewer: Yeah. 
Interviewee: Originally, I was gonna talk about memories and places and how if something crazy happens even in a really typical space you're gonna always remember that when you're in that space. You're gonna remember the memory and when you think of the memory you're gonna think of the space. Then as I started writing I realized that when I'm experiencing something I focus on certain things.

It's almost like my mind takes pictures of certain things and I remember certain details. I kind of wrote two different stories and then retold those stories and talked about - I try to incorporate the certain things that I was seeing as they happened. Certain things that I focused on or that stood out in my mind I tried to convey that.

Interviewer: Okay. How did that affect your writing process or your understanding of writing?

Interviewee: [Pause] The thing it showed me that I needed to be like-I don't know if explicit is the right word-but more descriptive because the way that I'm gonna describe something that I'm remembering-I know what happened. It happened to me so then to convey that to other people you have to be a lot more descriptive.

\section{Interviewer: Okay.}

Interviewee: To get people to feel the emotions that you felt is really hard because, obviously, when I think back about some of that stuff I remember how it felt but other people don't know how it felt. To get them to feel that is like you have to try a lot harder [laughter].

Interviewer: I see. Anything else that you experienced in the capstone course that was beneficial or transformative at all?

Interviewee: Well, I think one of the coolest things about the capstone course and just the writing minor in general was getting exposure to a lot of different people and different kinds of writing. There were people writing - people from all concentrations that do this. Some people wrote fictional novels and some people did professional pieces and some people did podcasts. It was really interesting to see all the different ways that writing can present itself.

Interviewer: Mm-hmm. Okay, so the community component was-?

Interviewee: Yeah.

Interviewer: I see. What did you learn from people in the class? From looking at others' writing. 
Interviewee: I saw that there were a lot of different ways to say something, if that makes sense. It depends who you're saying it to and why you're saying it. I realize you have to think- there are a lot more decisions that go into how you want to convey something.

Interviewer: What are some of those decisions?

Interviewee: Like how do you want to-do you want it to be in an essay? Like literally words on a page or do you want to turn it into something with pictures or do you want to put it on a website? All of the things that play into that.

If it's just an essay anyone can read it but then if you put pictures with it you're influencing people to see a certain thing or if you put it on a website then how do people navigate your website and where is the emphasis? There's so many decisions that go into that.

Interviewer: Makes sense. The next few questions are about your capstone ePortfolio. Go ahead and pull it up and I'll wait.

Interviewee: Okay.

[Break in Conversation 00:38:10 - 00:38:21]

Interviewer: Okay, let me just open up my questions. Sorry, hold on. Can you tell me about the most memorable aspect of your experience with the portfolio? Oh, it looks good.

Interviewee: Thanks. I think just deciding what kind of theme I wanted it to have.

Interviewer: Uh huh.

Interviewee: 'Cuz with my gateway portfolio I kind of went a little overboard with trying to force it into having a theme and I wrote this cheesy introduction. I think with this one I just wanted it to be a lot simpler and I wanted it to have a title. [...].

Interviewer: [Laughter]

Interviewee: - and then also I talked about how I try to make my writing come alive now instead of writing an essay that fulfills a prompt and turning it in. I want it to feel like there's someone behind it.

Interviewer: Mm-hmm. What were some of your goals or aims as you were developing this website? 
Interviewee: I definitely wanted to keep things simple; I didn't want to try to over explain things or try to make extra statements about things that I didn't really, truly feel. Like my reflections are pretty short on stuff but I think that's okay 'cuz I think with my gateway I've tried to write too long of reflections and they don't mean as much to me because I'm just saying things to fill space.

Interviewer: I see what you're saying. Do you have any other comments about the design of this or how you put it together?

Interviewee: Originally, I tried it on WordPress [content management system] and then a couple of the other people in our class were doing Weebly [website creation and web-hosting service] and I liked that it was pretty easy to work with. It was fun to switch it over and be able to do a lot more with it. Some people made them to be professional portfolios and we complained about school like, "They don't really care about seeing this," so it was kind of cool 'cuz I could just do what I wanted with it. I could be personal and I didn't have to worry about keeping it super professional. It could be fun. The picture is from a dance club-

Interviewer: Oh, I see it.

Interviewee: - but I thought it looked really cool [laughter].

Interviewer: It's almost abstract.

Interviewee: Yeah, yeah. My friend took it [laughter].

Interviewer: Interesting.

Interviewee: It was kind of fun to be able to do that and write a more fun "About Me" section as opposed to a third person like, "Mostly I didn't go over this 00:41:23." I didn't want it to be stuffy at all.

Interviewer: $\mathrm{Mm}-\mathrm{hmm}$. Overall, what was the narrative that you were hoping to convey on this ePortfolio?

Interviewee: I think a lot of what I said on the homepage; just keeping things real and keeping things so that they felt genuine.

Interviewer: Yeah, I see what you're saying. Interesting. As you were putting up these different artifacts did you notice any relationships among your artifacts?

Interviewee: Yeah. The ones that I picked were all either ones that I struggled with. I think actually most of them were ones that I really struggled with but that I felt really good about after having written them because I felt like I overcame all the issues that I was having trying to write them in the first place. 
All the things from the gateway are kind of in the new style that I adopted or just sitting down and writing. Just writing what came to mind as it came to mind? Those are the three pieces that I included from the gateway.

Interviewer: Got it. Do you think that creating this ePortfolio has had an effect on your writing?

Interviewee: Probably not [laughter]. I don't know. I just put a bunch of stuff on a website. [Laughter] Yeah. You probably want me to say, "Yes," but-

Interviewer: No.

Interviewee: [Laughter]

Interviewer: I mean it's important for you to be honest. Let's see. Did you learn anything from the reflective writing in the ePortfolio? Both the evidence-based essay you wrote and the contextual reflections?

Interviewee: I think I just saw that I-I don't know. I think I've realized that I've become less concerned with trying to-oh, this is hard to articulate.

Interviewer: $\mathrm{Mm}-\mathrm{hmm}$.

Interviewee: I was concerned with trying to make things feel super shiny and pretty and polished. Like I don't want to have to write-I don't want to feel like I have to fill space and write a super-long reflection on something so it was kind of-

Interviewer: I see.

Interviewee: - nice to be able to put stuff up there, say what I wanted to say about it and then just - that was it.

Interviewer: Got it. Last question about the ePortfolio. What could people who are interested in writing development-including program administrators like those at [Sweetland Writing Center] — learn about writing development from your ePortfolio?

Interviewee: What could they learn about writing development from looking at my ePortfolio?

Interviewer: Mm-hmm.

Interviewee: Oh. [Pause] I mean I think that their-well, so I only included [laughter] - I only included pieces that I really liked on mine. I think in looking 
at my developmental essay it's pretty clear. I didn't include drafts or anything on there, either, so it's kind of just like final products. I don't really know.

Interviewer: What do you think they'd observe about your process or about your values as a writer over time?

Interviewee: Oh, I think that's only really apparent in the developmental essay. I don't really know that you can get a huge sense of that from just looking at one thing to the next. I think I do explain it in parts of my portfolio, too, that justkind of where I started as a writer. Coming into college feeling like I could just conquer these rhetorical analysis essays to then realizing that there's more to it than doing well; answering a prompt.

Interviewer: Mm-hmm, interesting. [Laughter] Wow. It's kind of hard to not read your essay.

Interviewee: Oh, really? [Laughter]

Interviewer: It's really fun to read.

Interviewee: Oh, God [laughter].

Interviewer: Let's see. Let me go back to this. I'm gonna ask you just a couple closing questions about the gateway course again.

Interviewee: $\mathrm{Mm}-\mathrm{hmm}$.

Interviewer: Comparing the gateway to the capstone course.

Interviewee: Okay.

Interviewer: How did your experience in the capstone compare to your experience in the gateway course?

Interviewee: I think that the gateway course felt a lot more structured to me. the capstone [pause] - it felt like where we have these certain things that we had to do and that we were all there for each other but in terms of what we actually did in class I don't know that it really impacted my writing that much.

We did some peer workshop stuff and towards the end of the semester it was pretty much just workshopping other people's stuff every class. The gateway, I felt like, just the assignments that we had to do in class - those, I think, affected me a lot more. Maybe it's also just because by the time I got to the capstone I had had that in the gateway and so I just felt like I was already kind of settled into who I was as a writer. 
Yeah, the capstone course felt more just - not like you're on your own - but we each had these things that we had to do and we had class time to talk about them with each other but it was kind of - that was kind of all of it.

Interviewer: Which one do you think got more out of?

Interviewee: Probably the gateway course just 'cuz that's where I really started to change my style of writing.

Interviewer: $\mathrm{Mm}-\mathrm{hmm}$. Did you notice any differences between the gateway and the capstone ePortfolio?

Interviewee: Yeah [laughter]. In terms of mine?

Interviewer: $\mathrm{Mm}-\mathrm{hmm}$.

Interviewee: Yeah. Like I said, my gateway portfolio. I was still trying to fit it into this - fit this theme and I tried to make a theme and really go with it. It just feels kind of cheesy now. I think with the capstone I was just kind of like, "Here's my stuff and here is what I think about it," and it was pretty simple. That might also be because I'm a senior now [laughter] and so it's like-

Interviewer: It's easier?

Interviewee: Yeah. Yeah, and also I don't want to say lazy but I didn't—I don't know. I think I probably spent more time on my gateway portfolio. I don't know if I spent a lot less time on the capstone one but I like my capstone one a lot better "cuz I think it just feels more genuine. 'Cuz it was just like, "Here are my thoughts," instead of trying to mold them into fitting a theme or sounding super pretty.

Interviewer: $\mathrm{Mm}-\mathrm{hmm}$, yeah. We hear your voice.

Interviewee: Yeah.

Interviewer: What have your experiences been? You mentioned a couple of examples but any other examples of working with other writers throughout the minor?

Interviewee: It's always really interesting to see maybe you'll say a certain sentence and half the class will be like, "I really liked it," and the other half will say, "No. Get rid of it." It's always interesting to see the personal-you know writing is such a personal thing. Reading other people's stuff is also a very personal thing and so it was interesting just to see that. We actually got into a couple debates in class a few times like workshopping people's stuff 
People saying, "No, I think it's good that she said this because of this reason," and then other people are like, "I don't think it works." It kind of show you the-I think it showed me that you just have to write what you want to write, then, 'cuz not everyone's always gonna love it anyway. Half the people might love it and half the people might hate it and so you may as well write what you want.

Interviewer: That's fair.

Interviewee: Yeah.

Interviewer: Any other takeaways from peer workshop or peer editing?

Interviewee: [Pause 00:51:31 - 00:51:43] I think just realizing honest feedback is really important because I got some feedback that-well, so our guidelines for giving feedback were like, "Be super nice." It's great to be super nice but then at some point you want to give your honest opinion on something just in case the writer actually agrees with what you say or they see something in what you say. I got some feedback that was just all pats on the back which that's not helpful to me, you know?

Interviewer: Mm-hmm.

Interviewee: Then I got some feedback that was very honest and it was like, "I don't like this and I think you should have done this," and I value that a lot more. I think that is kind of my personality a little bit; to be a little bit more honest with people. Not that I'm mean but [laughter]_-you know? It's like I've always tried to write my feedback to people in that way and I think it was reaffirmed this semester that I think that's important.

Interviewer: $\mathrm{Mm}-\mathrm{hmm}$, absolutely. Both of these courses in the writing minor emphasized reflective writing in various forms. How would you describe your experience with this kind of reflection?

Interviewee: I think it's cool to see how-I don't want to say how far you've come but just where you've ended up. 'Cuz where I ended up in this final project that I just did is so different from anything that I would've imagined myself doing coming in as a freshman. Coming in as a freshman I was coming off of AP English and heavy, rhetorical analysis like close reading type stuff.

I always liked the essays where you had a prompt and just through looking back in my old writing and doing all of the new writing that I've done I've really seen this shift into trying to write more personal stuff. I don't know if that's just 'cuz I never did it before so now it's this new, exciting thing that I want to try out but yeah, it's been cool to see that change. 
Interviewer: Are you still using reflection in your current writing? Whether it's assigned or voluntary.

Interviewee: Well, I had to do reflections for the ePortfolio [laughter]. Like am I going to continue to write reflections on future stuff or-?

Interviewer: Or even not necessarily writing out reflections but-

Interviewee: Yeah, or just like thinking about it?

Interviewer: Yeah.

Interviewee: Probably. I feel like I usually tend to think about stuff more or to look back on stuff. There have definitely been-I think even the project. I've been thinking about the project a lot lately, having just completed it and not necessarily wanting to go write a reflection but just kind of thinking about it in general. I don't know, through sharing it with people and stuff, too, I'm still thinking about, 'Oh, I wonder how they'd respond to this or this?' you know?

Interviewer: Mm-hmm. Sounds like the audience component kind of influenced your-

Interviewee: Yeah.

Interviewer: - reflection component.

Interviewee: Yeah.

Interviewer: Have you learned any new terms or concepts because of this reflective process?

Interviewee: Not really.

Interviewer: [Laughter]

Interviewee: [Laughter]

Interviewer: The minor program is still relatively new. Are there any suggestions you would have for instructors or administrators for this program?

Interviewee: I think if it's really supposed to emphasize reflective writing then maybe do more of that [laughter]? I don't know. Do you mean like the writing itself is supposed to be reflective or we're supposed to write reflections on the writing?

Interviewer: I think either way. 
Interviewee: Okay.

Interviewer: I think reflective writing can mean actual writing-

Interviewee: Okay.

Interviewer: - that is reflecting on previous writing or it can mean a mental step after writing-

Interviewee: Yeah.

Interviewer: - or before writing.

Interviewee: 'Cuz I think with the capstone - the developmental essay-I mean that's definitely reflective writing. I think the project that I ended up doing and actually the projects that a lot of people ended up doing were very personal and reflective and I think that was also because we're all seniors and so a lot of people used it as an opportunity to look back on college as a whole and write about certain experiences.

In that sense I think the capstone definitely did that. The gateway-I don't remember doing a whole lot of reflecting. Maybe we did. Nothing that really stands out to me.

Interviewer: What do you feel like you wish you had learned about writing from those courses that you still don't feel like you've learned or understood?

Interviewee: Like what do I wish I would've learned about writing?

Interviewer: Mm-hmm. Like things you still want to work on or things that you wish had been taught better.

Interviewee: Oh. Hmm. [Pause] This doesn't mean I think I'm a perfect writer.

Interviewer: [Laughter]

Interviewee: I'm just trying to think of other things. [Pause] I think learning more about different styles would've been cool 'cuz I feel like I—well, I kind of stuck myself in a rut.

Interviewer: In what rut?

Interviewee: The rut of literary analysis [laughter]. I think it would've been really cool to have to do-I don't know. I think it would've been cool to have to do some kind of project that—and I guess the gateway kind of did this with the 
repurposing and remediating stuff-but kind of do something where it was like you really learned about different styles.

I know a lot of people took [English course] or different classes that kind of did this for them but it would've been cool to see what really goes into writing a good personal narrative versus creative nonfiction, which I guess might be kind of similar-

Interviewer: [Laughter]

Interviewee: - or a fiction. You know?

Interviewer: $\mathrm{Hmm}$.

Interviewee: Just seeing all the different components that go into those different things, I think, would've been cool.

Interviewer: Instead of just doing the literary analysis?

Interviewee: Yeah, 'cuz I feel like it was like don't really know what is a standard component of writing a fictional story. I would have no idea where to begin. It would be cool to know how to do that.

Interviewer: Mm-hmm. Hmm. More generally, what do you think professors should know about teaching writing at the undergraduate level?

Interviewee: Hmm. [Pause] I think that some professors need to just be careful with expecting a paper to fit a certain mold or expecting someone's ideas to fit a certain mold. 'Cuz I think I know I've seen that - I want to say with GSIs [Graduate Student Instructors] — and I know a lot of my friends and stuff have complained.

You know you get a paper back and they didn't like your-or what you said wasn't what they were looking for; what they seemed like they were looking for. I just turned in a paper to my anthro [anthropology] GSI that I hated but I thought it was what he wanted. You know I hate having to do that.

I guess just trying to be more open minded. I guess that's hard, though, 'cuz then it's like if they're a professor they know their field so they have the authority in that situation. I don't know.

Interviewer: Do you mean more in terms of the content-

Interviewee: Yeah.

Interviewer: - or the writing? 
Interviewee: I guess more in terms of content is what I'm talking.

Interviewer: I see.

Interviewee: In terms of writing I think [laughter] - it's funny because being a Sweetland tutor as well I see a lot of this where the rubric that's-I mean the rubric that someone brings in is, "Make sure you proofread. You'll lose points for grammar mistakes or spelling mistakes," and stuff but then a lot of these teachers don't teach grammar.

If you don't have the perfect grammar foundation coming into college where are you supposed to get that, you know? That's something we talk about a lot in the peer tutoring [laughter]. Yeah, 'cuz my freshman English teacher would take off points for every grammar mistake.

Interviewer: Here?

Interviewee: Yeah. We never really learned grammar and so people would fail the grammar portion of their essay grade and I had a pretty strong foundation with grammar from elementary school and up. I felt confident with that and I didn't really have a problem but for other people where are they supposed to get that?

Interviewer: Good question.

Interviewee: Yeah. I guess whatever you expect to see in the paper you should be teaching it. [Laughter]

Interviewer: [Laughter] Very well said. Any other final comments about teaching writing or the writing minor or the courses you've taken here? Your writing here.

Interviewee: I think the writing minor has just been a really great experience. It's weird 'cuz I can't put into words what I've gotten out of it but I know that my experiences here would've been different without it. I think it's just been cool to-honestly, the whole community aspect. The Sweetland community - this is something two of my really close friends are both peer tutors and in the writing minor.

We always talk about how Sweetland feels like a community. The faculty are all great and you get to know each other because the classes are smaller and stuff. It's just cool to see people from all different concentrations but all have this similar interest in writing but different interests show themselves in different ways with the different types of writing that people do.

The different ways that they present it. I don't know. I've encouraged a lot of people to apply for the writing minor because I think it's a really great experience 
and it's cool to have it to balance out all the science classes, too. It's really nice to have a couple writing classes here and there.

Interviewer: Great.

Interviewee: Yeah.

Interviewer: All right. Thank you.

Interviewee: You're welcome.

[End of Audio] 